\title{
Cine y procesos migratorios
}

\author{
Juan Manuel Goig Martínez \\ Profesor Titular de Derecho Constitucional \\ Universidad Nacional de Educación a Distancia
}

Recibido: 27.04.2011

Aceptado: 31.05 .2011

Resumen. Los desplazamientos humanos en busca de mejores condiciones de vida desde un punto de vista económico, social y cultural ha sido una constante en la historia de la humanidad. El incremento de los flujos migratorios constituye, especialmente en los últimos años, una fuente de preocupación creciente para los gobiernos, organizaciones internacionales y la propia sociedad. El presente artículo analiza cómo el cine ha entendido y mostrado los fenómenos migratorios y su trasfondo político, económico y social, especialmente en el caso español.

Palabras clave. Cine, multiculturalidad, procesos migratorios, globalización.

Abstract. Human mobility episodes in the pursue of better life conditions from a economic, social and cultural point of view have been a big issue in the human history. The increase of migratory flows constitute, specially in the last years, a source of concern for governments, international organizations and even the society. This article analyzes how the cinema has understood and showed the different migratory flows and its political, economic and social aspects, specially within the Spanish case.

Key words. Cinema, multiculturality, migratory flow, globalization.

Sumario: I. Introducción. II. Cuestiones en torno a los flujos migratorios. Cine y migraciones. 2.1.Cine y diversidad cultural. Gestión de la diversidad: multiculturalidad e interculturalidad. III. Las migraciones en el cine español.

\section{INTRODUCCIÓN}

La historia de la humanidad muestra que el desplazamiento de poblaciones como consecuencia de guerras, persecuciones políticas o religiosas, hambrunas, comercio de esclavos, conquistas, cautiverios o colonización, ha sido una constante a lo largo de los siglos.

Los desplazamientos humanos en busca de mejores condiciones de vida y de horizontes personales más amplios han existido siempre. La emigración es un hecho social, un derecho natural de la persona vinculada al principio de libertad ${ }^{1}$.

\footnotetext{
${ }^{1}$ POLO SÁNCHEZ, M M ${ }^{\mathrm{a}}$.C.- Derechos fundamentales y libertades públicas de los traba-
} jadores extranjeros en España, Madrid, CES, 1994, pág. 25. 
Desde los primeros tiempos, el hombre ha salido de su territorio para la conquista de nuevos territorios o para la búsqueda de mayor fortuna. Sin embargo, las causas de la emigración han experimentado un profundo proceso de trasformación. El movimiento de personas fuera de las fronteras de los Estados de los que son nacionales es el resultado, entre otras causas, de la pobreza extrema, la discriminación racial o sexual, los conflictos internos, la falta de oportunidades o la reunificación familiar.

El incremento de los flujos migratorios constituye fuente de preocupación creciente para los gobiernos, la sociedad civil y los organismos internacionales e intergubernamentales, ya que estos flujos tienen una gran repercusión en las relaciones sociales, culturales y políticas, no sólo entre los países de origen y receptores de la inmigración, sino también internas.

En el proceso actual de trasnacionalización de la toma de decisiones políticas y de globalización política y económica, la regulación jurídica de la extranjería ha cobrado un especial interés para la Comunidad Internacional que se ve sobrepasada por el fenómeno de la inmigración.

Si los marcos de convivencia entre extraños sobre un mismo territorio han oscilado entre las posiciones de dominio y fraternización, lo característico en nuestra época es que estos marcos de convivencia ocurren en magnitudes amplísimas en lo territorial, y muy numerosas en aspectos de población.

Los flujos migratorios inciden, de manera importante en la aparición del fenómeno de la multiculturalidad, íntimamente vinculado a los derechos humanos, que en un espacio de globalización se relacionan directamente con el ideal universalista de los mismos.

Desde finales del Siglo XX asistimos a la transformación de las sociedades demo-liberales. Nuestras sociedades ya no son sociedades homogéneas y armónicas. La primera transformación de la sociedad implicó su evolución hacia formas culturales plurales en las que, junto a claras diferencias, existían puntos en común que permitían la cohesión social y la convivencia entre diferentes. Pero en la actualidad, también nuestras sociedades han dejado de ser sociedades plurales en las que conviven diferencias pero que admiten una armonía que habilitan para una convivencia pacífica. Hoy en día, las sociedades avanzadas se han transformado en sociedades en las que conviven diferentes posturas en lo cultural y en lo político, y entre las que no cabe desechar aquellas que son contrarias a los viejos modelos y a sus principios, y en las cuales, la convivencia no es ajena al surgimiento de conflictos. Esta diversidad cultural no constituye un modelo normativo planificado de cómo debe de ser la sociedad, sino que constituye un hecho que se impone y que implica la coexistencia de grupos con códigos de conducta que se oponen radicalmente, y entre los que pueden surgir puntos de fricción. ${ }^{2}$

${ }^{2}$ MARTÍNEZ DE PISÓN CAVERO, J.- "Ciudadanía e inmigración en las sociedades multiculturales" en Ciudadanía e inmigración, POMED SÁNCHEZ, I Y VELASCO CABALLERO, F (eds), Monografías de la Revista Aragonesa de Administración Pública VI, Zaragoza 2003, pás. 21 y 22 . 
Los procesos migratorios ha sido un elemento dinamizador del pluralismo cultural, puesto que la llegada de nacionales de terceros países implica la convivencia en el Estado receptor de grupos y minorías marcados por su propia cultura.

Desde finales del siglo XX, la inmigración ha transformado la sociedad y ha supuesto un desafío a la propia definición identitaria que conlleva la presencia significativa de inmigrantes de otras razas, culturas y religiones. En este sentido, las distintas manifestaciones artísticas, entre ellas el cine, han ido respondiendo poco a poco a esa presencia del "otro", contribuyendo decisivamente a construir el imaginario colectivo sobre la inmigración y los inmigrantes.

\section{CUESTIONES EN TORNO A LOS FLUJOS MIGRATORIOS. CINE Y MIGRACIONES}

Aunque el tema de la inmigración, pueda parecer un tema especialmente económico, no constituye la inmigración un tema exclusivamente económico, que sin duda lo es, puesto que la inmigración, tanto regularizada como no regularizada, determina la convivencia de distintas culturas.

Este trasfondo, y la diversa apertura de la comunidad en que se manifiesta la diversidad cultural, son fenómenos que, en mayor o menor medida, van a determinar un mayor o menor grado de pluralismo que desembocará en un mayor o menor nivel de racismo y xenofobia.

Y ello constituye, además, un aspecto no concluido puesto que la periferia seguirá teniendo muchos problemas económicos y sociales, y en muchos lugares estos problemas empeorarán debido al aumento constante de la población y, sobre todo, de la desigualdad, lo que derivará en el incremento de los flujos migratorios y el paralelo incremento de los problemas económicos y de convivencia y en la posible aparición de enfrentamientos y conflictos ${ }^{3}$.

Temas como la extranjería o la inmigración son objeto de preocupación en cualquier sociedad, pero pueden serlo de manera diferente sobre la base de determinados criterios. En primer lugar podemos partir de cual sea el modelo constituido de sociedad dependiendo de los factores sociales que la sustentan. La civilidad y madurez de las diferentes sociedades será medible en términos de capacidad de acogida ordinaria de cuantos buscan protección, y de gestión de la diversidad cultural, en función de acontecimientos difícilmente previsibles.

No podemos obviar que las migraciones, además de la profunda huella que dejan en las sociedades de origen, contribuyen a formar y transformar las

\footnotetext{
${ }^{3}$ KERBO, H.R.- Estratificación social y desigualdad, Madrid, Mc Graw Hill, 1998, pág. 285.
} 
sociedades de destino. Las personas inmigrantes contribuyen a la economía, e inciden en la sociedad del país de acogida, pero a su alrededor también se detectan problemas. La inmigración es una realidad en términos cualitativos y cuantitativos que altera la sociedad, pero ello no debe de producir miedo.

Junto al modelo de sociedad, también constituye un factor importante la actitud de los Estados ante la inmigración y su proceso evolutivo. Esta actitud no siempre ha sido la misma y ha oscilado entre una total falta de actuación y una preocupación por el número excesivo de inmigrantes.

El reconocimiento de derechos constituye uno de los pilares básicos de la inmigración y su integración, puesto que su ausencia hace a los inmigrantes más vulnerables en su interacción diaria con la sociedad e institucionalizan diferencias entre los inmigrantes y los demás ciudadanos. La normalización de la situación de los inmigrantes constituye, y debe ser observada como un bien público que nos beneficia a todos.

Por ello, es preciso el avance normativo que promueva la participación de las personas inmigrantes, separando el tratamiento de los distintos aspectos que se relacionan con la inmigración de la lucha partidista, y la coordinación, cohesión y armonización de las políticas de integración, coherentes con las políticas de control de flujos migratorios.

El proceso migratorio y las respuestas que se ofrezcan a este proceso, nos deben de ofrecer los datos suficientes sobre la necesidad de reconstruir la ciudadanía ${ }^{4}$ y la democracia misma, para aproximarnos a las exigencias de un pluralismo tomado en serio en una democracia que intente reducir la exclusión ${ }^{5}$.

El cine ha reflejado desde sus inicios los dramas humanos de la sociedad, entre ellos la necesidad de dejar su propia tierra para sobrevivir. Y este reflejo que ha realizado el cine, no solo ha mostrado las migraciones externas, sino también las internas.

No se puede entender el desarrollo del cine sin el papel de los emigrantes, que fueron quienes levantaron esta industria. Estados Unidos es un país constituido por emigrantes, como se ha podido ver en miles de películas. El cine, como documento cultural, ha servido para narrar gran parte de las epopeyas europeas, afroamericanas y asiáticas en menor medida. El nacimiento de la industria del cine está demasiado cerca de la conquista del Oeste, siendo inabarcable el número de películas americanas que muestran estos procesos migratorios internos.

\footnotetext{
${ }^{4}$ Como indica Oliván, el concepto de extranjero es una creación del pensamiento liberal de la Revolución francesa. Con el concepto de extranjero se sustituye el concepto de súbdito por el de ciudadano. OLIVÁN, F.- El extranjero y su sombra: crítica del nacionalismo desde el derecho de extranjería, San Pablo, Madrid, 1998.
}

${ }^{5}$ DE LUCAS, J.- Op. cit, pág. 131. 
Basada en la novela de Steinbeck, John Ford muestra el proceso migratorio interno en los EEUU en Las uvas de la ira (John Ford, 1940) película en el que una familia campesina pierde durante la Gran Depresión su pequeña granja en Oklahoma y se ve obligada a buscar una nueva tierra de promisión en California. Durante su viaje deberán aceptar trabajos de jornadas agotadoras, sufrir el rechazo social y vivir en unas condiciones infrahumanas. Otros films de temática similar son Georgia (1981, de Arthur Penn), que narra la historia de inmigrantes de Indiana que se establecen en Chicago para trabajar en las grandes empresas acereras o Avalon (1990, de Barry Levinson).

El fenómeno migratorio ha sido reflejado por el cine, en términos generales, en todos los ámbitos geográficos. Pelle, el conquistador, (Bille August, 1987), cuenta la historia de un padre campesino y su pequeño hijo, que en el siglo XIX deben escapar de la pobreza en su Suecia natal e inmigrar hacia Dinamarca, donde sobrellevarán una durísima existencia. El film bolivianoargentino Bolivia, (Israel Adrián Caetano, 200) nos muestra la historia de un inmigrante boliviano en la Argentina. Una película muy interesante de los últimos años es In this world, (Winterbotton, 2003), que nos cuenta en tono de falso documental el viaje de dos jóvenes afganos que quieren llegar a Londres.

Aunque, no podemos obviar que ha sido la emigración a EEUU, por sus consideraciones político-sociales, por el volumen de inmigrantes, y, también, por la fuerza de la industria cinematográfica norteamericana, la que se ha mostrado en mayor número por el séptimo arte.

En clave de humor con todos los ingredientes de un duro viaje de emigrantes hacia América, Chaplin relata en El emigrante (Charlie Chaplin,1917) las peripecias del proceso migratorio, reflejando, de alguna forma, sus experiencias como emigrante. El emigrante que mayor impacto ha causado en la historia de la cinematografía moderna fue Charles Chaplin, lo que ha determinado su fijación por la defensa de los más desfavorecidos a lo largo de toda su obra. Pese a su éxito no olvidó nunca sus orígenes miserables en el East End de Londres, que se filtrarán en el problema de la emigración a lo largo de toda su carrera cinematográfica, alcanzado su cenit en La Quimera del Oro y El emigrante.

No podemos obviar que, durante un período largo de tiempo, el sueño americano ha sido uno de los objetivos a conseguir por los emigrantes, y ello ha quedado perfectamente reflejado en el cine mediante la narración de historias de emigrantes provenientes de todas las partes del mundo. América, América (Elia Kazan,1963), nos muestra la obsesión de Stavros, un joven griego, de llegar a los Estados Unidos de América lo que le lleva a iniciar y finalizar con éxito la aventura de la emigración. Los emigrantes (Jean Troell, 1971), relata las dificultades de los campesinos suecos por lograr en sueño americano. Más recientemente, el documental Which way home, (Rebecca Cammisa, 2010) candidato a los Oscar, también retrata las historias cotidianas de los inmigrantes que tratan de entrar a Estados Unidos, en este caso a través de la mirada de los niños que viajan completamente solos con el sueño de alcanzar una mejor vida. 
Una parte fundamental de la Historia de los Estados Unidos está recogida en su cine, forjado por mujeres y hombres de las más variadas procedencias. El tema del emigrante ha sido tratado de manera reiterada desde Un sueño americano (1944 de King Vidor), aunque actualmente, la visión es poco o nada trascendente, abundando el folklorismo y los tópicos que contribuyen a no crear una visión demasiado coherente de los colectivos que llegan a Norteamérica. Debemos hablar de una visión estereotipada de la figura del emigrante en la cinematografía norteamericana, determinada hacía colectivos excluidos socialmente y participantes en actividades ilícitas. Así los italoamericanos estarían ligados al mundo de la mafia, los hispanos al tráfico de drogas, los afroamericanos a los sectores más desfavorecidos y violentos de la sociedad y los nuevos emigrantes de Europa del Este a todos los negocios ilegales posibles. Algo mejor aparecen los orientales, fundamentalmente porque se han mantenido al margen y la asunción de su identidad milenaria no ha dejado que sus problemas como colectivo se vislumbren tan claramente como los de los anteriores ${ }^{6}$.

La experiencia migratoria a EEUU ha puesto de manifiesto, además, los graves problemas que rodean la inmigración: la inmigración irregular; la explotación del trabajador inmigrante; la política migratoria americana, o las mafias de inmigrantes, $\mathrm{y}$, por supuesto la xenofobia y el racismo.

En Pan y rosas (Bread and Roses, 2000, de Ken Loach), las protagonistas son dos hermanas mexicanas, limpiadoras en un edificio de oficinas de Los Ángeles, que emprenden una campaña de lucha contra sus empleadores.

También la situación de irregularidad de los inmigrantes ha adquirido un especial interés para el cine. Alambrista, de Robert M. Young (1977), muestra la dramática situación de los trabajadores mexicanos indocumentados. Tema que también es abordado en 1982 en La frontera (Tony Richardson). Trabajo clandestino (Jerzy Skolimowski, 1982) nos muestra el aislamiento y reclusión de un trabajador de origen polaco que vive escondido junto con sus compañeros en la casa en la que trabaja.

Border War (The Battle over illegal inmigration -Guerra en la frontera:la batalla contra la inmigración ilegal-) es el nombre del documental, producido por la asociación conservadora norteamericana Citizens United, de 92 minutos de duración, en el que se califica de "delincuentes" a inmigrantes indocumentados que cruzan la frontera Mexicana hacia Estados Unidos.

Más recientemente, La frontera infinita, del mexicano Juan Manuel Sepúlveda, ahonda en la experiencia de miles de centroamericanos que cada año intentan llegar a Estados Unidos, mientras los norteamericanos debaten la po-

\footnotetext{
${ }^{6}$ Fernando Roncero Moreno y Juan Agustín Mancebo Roca, Inmigración, emigración y cine, http://www.uclm.es/profesoradO/juanmancebo/descarga/publicaciones/Imnigraci\% C3\%B3n,\%20emigraci\%C3\%B3n\%20y\%20cine\%20bueno.pdf
} 
lémica ley impulsada en el estado de Arizona que criminaliza la presencia de inmigrantes indocumentados.

La inmigración irregular ha venido de la mano de la explotación del inmigrante y de la existencia de mafias migratorias.

El tema de las mafias en la inmigración se muestra perfectamente en el film británico Ghosts, dirigida por Nick Broomfield en 2006. Es una película basada en hechos reales. Es la brutal realidad de un mundo secreto que nos rodea. Ai Qin, una joven de la provincia de Fujian, China, pide prestados 25.000 dólares para pagar a la banda de los Snakehead, quienes la llevaran ilegalmente al Reino Unido y asi poder enviar dinero a su familia para mantener a su hijo. Una vez ha llegado al Reino Unido se convierte en una mas de los tres millones de inmigrantes ilegales que conforman la espina dorsal de la cadena alimenticia, la construcción o la industria hostelera. Ai Qin termina viviendo en una casa suburbial de dos habitaciones con otros quince compatriotas. Con un permiso ilegal trabaja en una fábrica preparando comida para supermercados ingleses. En su búsqueda de trabajos mejor pagados para devolver la deuda, terminan mariscando por la noche en la Bahía de Morecambe. El 5 de febrero del 2004 veintitrés de ellos se ahogaron en Morecambe. Sus familias en China aún están pagando sus deudas. Ai Qin y otros personajes principales son protagonizados por personas que han sido inmigrantes ilegales y se han sumergido en sus pasadas experiencias para dar unas actuaciones apasionadas y auténticas.

La explotación del inmigrante por las mafias migratorias también se ve reflejada en La mosca en la ceniza, de Gabriela David, que se adentra en la vida de dos jóvenes amigas de un pueblo que llegan a Buenos Aires sin imaginar que serán obligadas a prostituirse por una red de trata de personas. Abril, de Nanni Moretti (1998), recoge imágenes de la manifestación de 1994 contra el racismo y de la llegada, al puerto de Bríndisi, en la primavera de 1997, de un carguero lleno de albaneses.

\subsection{Cine y diversidad cultural. Gestión de la diversidad: multiculturali- dad e interculturalidad}

El fenómeno de la inmigración ha dado lugar a que los Estados receptores hayan visto modificado el paisaje de la vida cotidiana, en la que conviven minorías muy significativas numéricamente, que han dado lugar a una amplia diversidad cultural.

Como ha indicado VÁZQUEZ GONZÁLEZ7 ${ }^{7}$, la globalización, en lugar de favorecer la convergencia de una cultura global, caracterizada por una ho-

${ }^{7}$ VÁZQUEZ GONZÁLEZ, C.- Inmigración, diversidad y conflicto cultural. Los delitos culturalmente motivados cometidos por inmigrantes (especial relevancia a la mutilación genital femenina, Dikynson, Madrid, 2010, pág. 34. 
mogeneización y un acercamiento cultural en el que se unificaran modos de vida, símbolos culturales y conductas, ha otorgado una relevancia importante a las identidades étnicas y culturales, tanto en la configuración de los nuevos espacios nacionales, como en la emergencia de universos identitarios como referentes de articulación de la convivencia colectiva.

El desarrollo alcanzado por los procesos migratorios, ha dado lugar a la diversidad cultural.

Los diferentes modos de gestión de la diversidad, se han situado, en la práctica, entre dos modelos radicalmente opuestos: el monoculturalismo y el multiculturalismo.

Llevadas a su visión más extrema, ambos modelos se basarían en dos prejuicios opuestos: que todo hombre es igual a otro, y que todo hombre es diferente a otro ${ }^{8}$

Desde una primera actuación, caracterizada por la segregación o la guetización, definida por la exclusión y separación física y legal de los diversos grupos, el modelo monoculturalista, evolucionó hacia el modelo de la asimilación.

En el ámbito migratorio, la asimilación pretendió que los grupos de inmigrantes debían, paulatinamente, identificarse con los habitantes del país receptor no sólo en el ámbito legal, sino en el cultural, de manera que había que aceptar sus costumbres, su lengua y sus tradiciones, perdiendo la propia identidad. En el trasfondo de estas actitudes se observaba la idea de la superioridad de los patrones culturales de la mayoría dominante, y esta superioridad habilitaba a su imposición sobre posiciones culturales diferentes. Esta política migratoria, que fue la adoptada en Francia, se observa magníficamente en la película Cheb, (Rachid Bouchared, 1990) sobre un joven argelino que vive en Francia desde su primer año y con 19 se hace expulsar y vuelve a Argelia, donde es forzosamente enrolado, en un universo que le resulta hostil, sintiéndose inmigrante en todas partes.

Una segunda visión de las posiciones monoculturales, ha sido la mal llamada "integración" que, al igual que la asimilación, pretendía la eliminación, o sometimiento, de la diferencia, pero basada en el reconocimiento generalizado a todos los individuos, de los mismos derechos civiles y políticos, aunque sin reconocer los derechos culturales de los individuos y su diversidad, hecho que diferencia aquella integración de los procesos de integración que vivimos en la actualidad.

Esta "integración" que se observa en los primeros momentos, y que busca la homogeneidad en el ámbito universalista de los derechos civiles, supuso un avance respecto a la asimilación, pero huía de la reafirmación de la diferencia identitaria.

${ }^{8}$ Vid. BOBBIO, N.- "Iguales y diferentes" en BOBBIO, N, Elogio de la templanza, Temas de hoy, Madrid, 1997. 
Hoy en día, la integración hay que entenderla como el proceso dirigido a conseguir la gradual incorporación y participación de los inmigrantes en la vida económica, social, política y cultural de un Estado, en un clima de respeto y participación recíproca.

Como reactivo a estas políticas migratorias, surge la multiculturalidad, concepto en torno al cual no existe unanimidad.

El pluralismo cultural tiene sus raíces en las "sociedades plurales" para referir a sociedades donde coexistían colonizadores, colonizados e intermediarios en continua tensión. Como formulación de modelo o ideología, el pluralismo cultural surgió en EU y Europa a partir de los fracasos de los modelos asimilacionistas y del "melting pot", de la conciencia de lo que se puede llamar persistencia étnica, y de la formación de nuevas comunidades étnicamente diferenciadas. Sus principales fundamentos fueron la aceptación de la diferencia cultural y su valoración positiva; y el reconocimiento general de la igualdad de derechos y deberes.

Con algunas coincidencias, como el respeto a todas las culturas y el derecho a la diferencia, el multiculturalismo puso énfasis en la organización de la sociedad con el fin de que exista igualdad de oportunidades y posibilidades de participación en la vida pública y social para toda persona independientemente de su identidad cultural, etnoracial, religiosa o lingüística. El multiculturalismo se refiere a una situación de hecho (convivencia en un mismo espacio de personas con culturas variadas) y es también una propuesta de organización social (proyecto político de respeto a las identidades culturales). Sin embargo, como propuesta ha recibido numerosas críticas. Políticamente se le ha cuestionado en lo referente a una posible ruptura de la unidad nacional, así como de la creación de privilegios costosos hacia foráneos. Posiciones racistas y xenófobas también argumentan el derecho de los nacionales autóctonos a continuar siendo "ellos mismos".

El concepto de interculturalidad surgió a partir de las carencias de los anteriores conceptos, ya que pretendió reflejar una dinámica social más allá de la situación de estática cultural. Es un término más reciente y aún está en construcción. Tiene un carácter interdisciplinario al emerger del campo de la educación, la comunicación y la mediación entre culturas. La interculturalidad se refiere a una interacción entre agentes de culturas distintas en un tiempo y espacio determinado. Sería el "proceso de convivencia de dos o más culturas en una sociedad pluricultural, gracias a la cual es posible enriquecerse mutuamente a través de la apropiación de rasgos socio-culturales". Entonces, el desarrollo de una conciencia crítica y reflexiva acerca de la diferencia se convierte en uno de los grandes retos a enfrentar.

Dicha interacción implica una reflexión que permita superar las oposiciones dicotómicas (occidente versus no-occidente, modernidad versus tradicionalismo) que nos llevan a encapsular a las culturas a través de los estereotipos y estigmas creados a su alrededor. Entonces, el conocimiento del "otro" adquiere sentido e implica un proceso de aprendizaje que puede durar 
toda la vida. Desde una visión crítica que no sea manipulada o sesgada por la propia cultura se puede realizar un análisis de los aspectos positivos y negativos de las culturas de las personas que intervienen en la interacción. En este sentido, también hay cabida para la apropiación de rasgos culturales y sociales como medio de enriquecimiento cultural. Esto implica abandonar las perspectivas puristas que conciben la apropiación de forma pasiva y automática. La interacción de personas de diferentes culturas, que conviven en un mismo territorio y comparten una realidad similar, provoca rasgos compartidos y la continúa adopción y adaptación de éstos. Esto indica que la cultura no es algo estático y que sus portadores la transforman y adecuan constantemente.

Los encuentros e intercambios entre personas de diferentes culturas no implican necesariamente choques, conflictos o competiciones. El objetivo no puede ser la asimilación de lo extraño por medio del entendimiento y su aniquilación por medio del traslado a lo conocido", sino que hay que propiciar una apreciación positiva y respetuosa de la diferencia. Para alcanzar este objetivo se requiere, de inicio, propiciar una actitud de aprendizaje y conocimiento del "otro".

En esta línea, es igualmente peligroso caer en la polarización de la situación y suponer que todo lo diferente y extraño es positivo o representa un enriquecimiento cultural. De forma similar, entre los peligros de una visión purista de lo intercultural están el enaltecimiento de la elasticidad de las identidades o por el contrario, su esencialización. En el intento de evitar la uniformización se ha recurrido a una multiplicación desmesurada de las identidades en diferentes momentos y espacios, esto puede volverlas escurridizas e instrumentales. En el otro extremo, ante un contexto de mayor contacto entre diferentes culturas se recurre a la esencialización de las identidades y se vuelven entes estáticos. Estos aspectos pueden igualmente llevarnos a actitudes hostiles y xenófobas.

A pesar de que este término introduce una perspectiva dinámica de las culturas su denominación puede llevar a olvidar las dimensiones socioeconómicas y jurídicas, así como las desigualdades y jerarquías etnoraciales en que se da la interacción. Es necesaria la creación de condiciones materiales y sociales que permitan mantener la identidad cultural propia en espacios de convivencia multicultural, ya que esta desigualdad está entre las causas del por qué las personas niegan u ocultan sus identidades culturales.

No es esta, sin embargo la definición de multiculturalidad que defendemos. Como indica VELASCO ${ }^{9}$, el modelo multiculturalista parte de la valoración positiva del pluralismo y de que se debe permitir la diferente conservación más amplia posible de aquello que lo hace distinto: la propia

${ }^{9}$ VELASCO, J.C.- "El multiculturalismo, ¿Una nueva ideología?, en ALCINA, J y CALÉS, M (eds), Hacia una idelología para el Siglo XXI, Aikal, Madrid, 2000, págs. 152 y 153 
cultura, sin que ello implique la fragmentación cultural sin interacción. La multiculturalidad implica una doble negación: por un lado, la negación del universalismo abstracto y uniformador, según el cual el imaginario colectivo de todos los hombres sería idéntico y, por otro lado, la negación del particularismo, estéril por reduccionista, que pretende plantar a cada uno en el gueto de sus raíces.

La interculturalidad es un término muy reciente y todavía está en construcción. Efectivamente hace referencia a la dinámica social más allá de la situación de estática cultural, y tiene un amplio carácter interdisciplinar al emerger en el campo de la educación, la comunicación y la mediación entre culturas, pero, en puridad, no se ha desarrollado en su plenitud. Tiene un significado muy amplio que implicaría una renegociación continuada de los roles, espacios, a través de un discernimiento de los valores que unen, vinculan y orientan los procesos de síntesis, que implica una cadena perceptiva: las percepciones que yo tengo del otro, las que el otro tiene de mí y de cómo yo lo percibo ${ }^{10}$. Hablar de esta manera tan categórica de interculturalidad, implicará el riesgo de avanzar en la multiculturalidad sin haber alcanzado el respeto y la relación entre distintas culturas, que es lo que implica la multiculturalidad.

La multiculturalidad, es un hecho que connota diversidad cultural, la aceptación de la misma y el compromiso por dinamizar las relaciones culturales. La multiculturalidad -interculturalidad cuando se convierte en dinámica si queremos llamarla así- enriquece las relaciones y la democracia, ya que su perspectiva dinámica e interactiva se desarrolla en el ámbito de la mutua influencia, del sincretismo cultural, del deseo de un desarrollo global, enmarcado en los contextos de una sociedad cognitiva y global, y amparado por la revolución tecnológica.

La multiculturalidad promueve el pluralismo cultural y la no discriminación por razones de raza o cultura, el derecho al reconocimiento de la diferencia cultural y a su implicación en la organización social de la comunidad o grupo humano en el que se vive.

Esta nueva realidad social y cultural ha tenido, también, su reflejo en el cine. My family, de Gregory Nava (1995) aborda magníficamente el tema de la multiculturalidad a través de tres generaciones de una misma familia de inmigrantes mexicanos, que ven crecer la ciudad de Los Ángeles a su alrededor, mientras tratan de integrarse en la sociedad americana y conseguir sus sueños de prosperidad. En La nueva tierra (1972, de Jan Tröel),se observan los cambios culturales en una familia sueca emigrante en América. A finales del siglo XIX, una familia sueca emigra a Minesota. Van en busca de una vida mejor y más libertad y aunque no pretenden convertirse en americanos, la cultura de su nuevo país va influenciando cada vez más sus vidas.

${ }^{10}$ Vid. MANZINI, V.- Multiculturalidad, interculturalidad, conceptos y estrategias, Universidad de Bolonia, Bolonia, 2001. 
En Oriente es Oriente, de Daniel O’Donell (1999), se relatan las dificultades de la segunda generación de una familia de pakistaníes en el Reino Unido, que sólo aspira a integrarse en la sociedad en la que viven y olvidar la rígida concepción familiar de su padre. Quiero ser como Beckham (Gurinder Chadha, Gran Bretaña, 2002), a través de la comedia, pone de relieve problemas asociados a la inmigración en un Londres multiétnico, entre ellos el de la diversidad cultural y su gestión.

Llama la atención como estas dos últimas películas se desarrollan en Gran Bretaña, donde existe una amplia diversidad cultural, cuya gestión ha sido ampliamente desarrollada mediante políticas de integración adecuadas. Sin embargo, el cine ha reflejado los problemas de integración cultural en casi todas las zonas del mundo.Y ello lo podemos ver en películas como Side Streets (Tony Gerber, 1998), que refleja la vida en la periferia urbana multicultural, donde la vida se sitúa en el fondo de los rascacielos de Manhattan, como enclave étnico no monopolizado por un grupo particular. Otro buen ejemplo del género es $\mathrm{La}$ otra América (Goran Paskaljevic, coproducción de Francia / Reino Unido / Alemania / Grecia 1995) que también se sitúa en los enclaves de la multiétnica Nueva York. En Rabia (Karim Dridi, 2003), se muestra la historia de amor, ambientada en el barrio chino de París, donde un español se enamora de una niña china. Un dólar Curry (Vijay Singh, 2004) se centra en un protagonista Sikh que interactúa con un jamaicano y con un ruso, que protege prostitutas de la calle. Podemos encontrar películas ambientadas en ciudades como Viena, Nordrand (Albert Barbara 1999); Altona en Alemania: Und Schmerzlos Kurz (Akin Fatih 1998); en Oslo, del noruego Erik Poppe (1998) que narra la relación entre los inmigrantes de Yugoslavia y Pakistán y el tráfico de drogas en Oslo, o la visión multicultural de Copenhague, en las películas Empujador (1996) y Empujador de dos (2004), del danés Nicolas Winding Refn. Apo estano polis tis akri (Constantino Giannaris, Grecia, 1998) muestra el gueto multicultural de Atenas. Roto Inglés (Nueva Zelanda, Gregorio Nicolás 1996) narra la historia de una joven inmigrante croata que se enamora de un hombre nativo maorí, mientras que secretamente se casa con un hombre chino ilegal para ayudarle a emigrar. En Ciudad de las almas perdidas (Takashi Miike, Japón, 2000) se muestran las relaciones entre japoneses, brasileños, rusos y chinos, se desarrolla en barrios dominados por grupos étnicos mixtos.

\section{LAS MIGRACIONES EN EL CINE ESPAÑOL}

En el caso de España, donde las condiciones políticas y socioeconómicas de los años 40 a 60 , fueron especialmente difíciles, los procesos migratorios internos y externos, han quedado magníficamente reflejados por el cine.

Antes de los años 40 del siglo XX, la migraciones rurales fueron reflejadas con películas tan profundas y cargadas de dramatismo como las dos versiones que Florián Rey hizo de La aldea maldita, una en 1930, muda y otra sonora en 1942 
Ya en el franquismo, el cine español ha seguido reflejando la migración rural y sus dramas. Dos películas merecen una especial atención: Surcos (1951), que nos da a conocer los problemas de la emigración rural hacia la ciudad en la España de Franco, y La piel quemada (1967) de José María Forn, que lleva el problema de los emigrantes rurales en una patética plasmación del subdesarrollo económico y cultural español de la época.

Actualmente España es tierra de acogida; sin embargo, hasta la década de los noventa ha sido un país de emigración. A lo largo de la historia se han ido sucediendo y, en ocasiones, superponiendo distintos movimientos migratorios que respondían a causas sociodemográficas, económicas y/o ideológicas ${ }^{11}$.

La emigración española ha constituido un fenómeno constante, que se acentuó desde la segunda mitad del siglo XIX hasta más allá de mediados del siglo $\mathrm{XX}$.

Las grandes transformaciones demográficas, económicas y sociales que tuvieron lugar en el continente europeo entre 1840 y 1930 afectaron a millones de personas. Hombres y mujeres de todos los rincones de Europa protagonizaron un gran movimiento migratorio hacia el otro lado del Atlántico. La emigración española hacia América Central y del Sur formó parte de esta epopeya europea, y alrededor de 3 millones y medio dejaron el país con destino a América, en lo que vino a denominarse la "emigración en masa".

Este proceso migratorio se produce principalmente, por causas económicas, ya que a comienzos del siglo XX, España era un país de economía agraria escasamente modernizada, incapaz de generar trabajo y alimentos que mantuviesen los ya bajos niveles de vida de las generaciones anteriores. La evasión del servicio militar fue otro motivo para emigrar. Además, la información sobre las oportunidades económicas que existían en la otra orilla del Atlántico, era transmitida por familiares y amigos. El "efecto llamada", generó cadenas migratorias que tuvieron mucha importancia en las zonas de mayor flujo emigratorio. También fue relevante la acción de los agentes reclutadores al servicio de las políticas migratorias de los países latinoamericanos.

La emigración española hacia el Continente Americano también ha tenido su reflejo en el cine español. Interesantes son Frontera sur, 1998, en la que Gerardo Herrero hizo un drama de emigración en Argentina, o Sus ojos se cerraron de Jaime Chávarri, (1997), que narra la historia de una modista madrileña que llega a Buenos Aires en los años 30.

La Guerra Civil española y la dictadura, son las causas del primer gran éxodo migratorio de españoles en el Siglo XX. A partir de 1939 comienza a producirse un éxodo de refugiados políticos. El exilio ocasionado por la Gue-

${ }^{11}$ Un importante estudio sobre la migración española puede verse en GARCÍA LÓPEZ, J.R.- Las remesas de los emigrantes españoles en América: siglos XIX y XX. Júcar, 1992, y en MÉNDEZ VENEGAS, E.- Emigrantes a América (s. XVI-XVIII). Mérida, Regional de Extremadura. 1995 
rra Civil española y por la dictadura significó, sin duda, una pérdida para el desarrollo económico, cultural y social de España que, como contrapartida, determinó que los países que acogieron a los refugiados españoles pudieran beneficiarse con la formación académica, científica y profesional de los exiliados.

Tras el dramático éxodo político de la España republicana, la emigración económica de los españoles hacia Europa se inicia en la década de $1950^{12}$, y se trata de una emigración de carácter económico, motivada por las duras circunstancias de la posguerra que se viven en España, y atraída por las buenas perspectivas de trabajo y el mayor nivel de vida derivado del crecimiento económico existente en esos países.

Los factores que determinan este desplazamiento masivo de trabajadores al exterior en pleno régimen franquista son, por una parte, el notable incremento demográfico de España que provoca un excedente de mano de obra que las estructuras económicas, basadas en una economía rural y de escasa industrialización, no pueden absorber y, por otra, la expansión industrial y el crecimiento económico de los países europeos, pero también, el gran éxodo español coincidió con la necesidad de mano de obra en Europa, que se recuperaba de los estragos producidos por la Segunda Guerra Mundial, reconstruyendo ciudades.

Los gobernantes de la época fomentaban la emigración, pues aliviaba la escasez de trabajo y permitía ingresos en divisas para las arcas del Estado. Y es que no podemos olvidar que la emigración de la década de los años sesenta, así como la de las décadas anteriores, tuvo efectos beneficiosos, tanto para el trabajador, que tenía la posibilidad de obtener un empleo mejor remunerado y de mejorar su cualificación profesional y sus condiciones de vida, como también para el crecimiento económico de España, ya que la entrada de divisas enviadas por los emigrantes permitió sufragar parte del déficit comercial y equilibrar la balanza de pagos, facilitando las importaciones de bienes de equipo destinados a la modernización de las empresas. Esta situación contribuyó en gran medida a la expansión industrial de España en los años sesenta y setenta.

La otra cara del proceso migratorio ponía de manifiesto, junto a estos efectos beneficiosos, que la realidad de la emigración y del exilio, también implica la existencia de consecuencias negativas para los trabajadores emigrantes, los exiliados y sus familias derivadas del desarraigo social y cultural

${ }^{12}$ Durante esa década el principal destino migratorio español siguieron siendo los países americanos. Pero no son los únicos: otra importante masa de trabajadores no cualificados inicia un éxodo económico hacia Europa: Francia, Alemania, Suiza, Bélgica, Países Bajos, Inglaterra... También hacia América, con cifras muy importantes: en 1950, 55.314 españoles embarcan para países del área hispana: Argentina, Uruguay, Venezuela..., y en 1955 salen para ultramar 62.237 españoles. 
de España, y, sobre todo, de las dificultades de inserción social y laboral en el país de acogida y de los problemas que habían de abordar en su proyecto de retornar a España, aspectos estos últimos, que los poderes públicos españoles, en un primer momento obviaron, y sólo muy tardíamente contemplaron de una manera muy tímida.

No existían derechos y libertades en aquella España, pero, además de poder hablar de españoles de primera y de segunda, por su condición política, también existía una ciudadanía española muy dispar por razón del país en que se vivía.

En el franquismo los españoles salían de España y películas como Españolas en París (1970) de Roberto Bodegas o Vente a Alemania, Pepe (Mariano Ozores,1971), reflejan, en clave de humor las vicisitudes socioeconómicas, y la situación de irregularidad en la que salían los españoles, que era más frecuente que la que mostraban las autoridades de la época, y los problemas de integración cultural. Aunque abordando este mismo tema, la película contemporánea más interesante es Un franco, 14 pesetas, (2006) de Carlos Iglesias, que narra una historia de españoles emigrantes a Europa hacia 1960, basada en vivencias del propio director en la que desmitifica muchas de las aseveraciones sobre la emigración de españoles que actualmente se tienen, así como del retorno a su país de estos emigrantes. Las dificultades de adaptación, la entrada sin papeles, los problemas, la necesidad de sobrevivir, a veces delinquiendo, etc. También en 2006, Marta Rivas y Ana Pérez han retratado en el documental El tren de la memoria, el éxodo de dos millones de españoles que buscaron la prosperidad en Europa en los años sesenta. Se fueron para unos meses, se quedaron treinta años. El documental pretende cubrir una laguna en la reciente historia de España y saldar una deuda con los protagonistas de unos tiempos difíciles de los que apenas sabemos algo más que una escueta historia oficial y unos cuantos tópicos. La mitad son clandestinos y viajan sin contratos de trabajo. El ochenta por ciento son analfabetos. Ante ellos se levanta el muro del idioma y las costumbres diferentes.

La integración europea y la disolución de las barreras económicas han aumentado tanto el intercambio cultural como el comercial. El movimiento de bienes y servicios lleva también consigo el flujo de personas, sobre todo de trabajadores migrantes, y en particular su movimiento desde las zonas más pobres (Europa del Este, América Latina y el Caribe, el Magreb, el África subsahariana) hacia el norte y el oeste, a las naciones consideradas generadoras de riqueza. La Unión Europea registra una inmigración anual legal de unos 1.2 millones de personas, y se calcula que llegan otros 500,000 ilegales anualmente. En España, uno de los países en el fulcro del cambio, el Instituto Nacional de Estadística calcula en 4.69 millones el número de residentes extranjeros, de los cuales aproximadamente 1.69 son indocumentados. De aquéllos, muchos son expatriados del norte de Europa, jubilados y de situación económica acomodada; pero una gran parte del resto procede de regiones muy pobres. 
El cambio de la situación económico-social en España trajo consigo una nueva realidad y llegaron los emigrantes.

Y es que, España ha pasado a ser un país de inmigración. Con el incremento de los flujos migratorios que se ha registrado en los últimos diez años, España se ha situado en los niveles de la UE en la proporción de extranjeros que reside en nuestro país, de manera que las oportunidades y desafíos que plantea la inmigración son similares a los que afrontan otros países europeos, y, además, la conversión de España en un país de inmigración es un proceso continuado en el tiempo que se mantendrá, seguramente durante varias generaciones. Ello exige una política adecuada y duradera en materia de inmigración, que debería estar presidida por el consenso, el diálogo y la formulación, así como por la cooperación entre las distintas Administraciones Públicas interesadas en el tema.

Las migraciones están configurando en España una realidad social más compleja, más rica, más heterogénea, caracterizada por la diversidad cultural, y la inmigración se configura como un fenómeno positivo, beneficioso y deseable para España, y para el conjunto de la UE, no solo desde el punto de vista laboral, demográfico o económico, sino también social, cultural, religioso y político.

La inmigración es una realidad que está en constante cambio. Por ello, el legislador está obligado a adaptar su normativa reguladora, si quiere que la misma proporcione soluciones efectivas a los nuevos retos que se plantean.

Además, el fenómeno migratorio ha adquirido tal dimensión en España y tiene tales repercusiones en el orden económico, social y cultural que exige que por parte de los poderes públicos se desarrolle una actuación decidida en diversos frentes, incluido el normativo. Por lo tanto, los poderes públicos deben ordenar y canalizar legalmente los flujos migratorios de tal manera que los mismos se ajusten a nuestra capacidad de acogida y a las necesidades reales de nuestro mercado de trabajo.

Estos cambios en población y en pautas demográficas van acompañados de un aumento correspondiente de conflictos étnicos y tensiones raciales, y una auto-indagación sobre lo que significa exactamente ser "español". España, situada en la confluencia de varias rutas inmigratorias a Europa, ha visto, además de las tensiones ya existentes entre sus etnias indígenas (gitana, vasca, catalana), un incremento paralelo en problemas sociales y confrontaciones entre ciudadanos autóctonos e inmigrantes extranjeros.

El cine comenzó a relatar la forma de vida de los recién llegados, sus problemas, sus dificultades de integración, las trabas administrativas y personales, y los problemas de oposición, racismo o xenofobia, también han tenido su reflejo en el cine español. Las cartas de Alou, de Montxo Armendáriz (1990), narra el periplo de un joven senegalés por la península en precarias condiciones laborales La película trata, en esencia, el movimiento, el desarraigo, y el continuo desplazamiento del exilio cuya vida está dictaminada por el mercado laboral informal, la discriminación racial y la separación de la 
familia . Los inmigrantes subsaharianos y los magrebíes, con quienes traban amistad en miseria compartida, camaradería y oraciones musulmanas, habitan un submundo de pisos desmantelados, "sweatshops", edificios abandonados y túneles oscuros.

Una interesante reflexión sobre la xenofobia y el racismo encarnados en una familia española, sus miedos y sus frustraciones hacia un emigrante subsahariano que acaba de llegar en patera, podemos ver Bwana, de 1995, de Imanol Uribe. Bwana, repite varios de estos temas pero los problematiza mediante un estudio de carácter más complejo que el estilo seudodocumental de Armendáriz. Por las reacciones y comentarios de la familia hacia el recién llegado, quien siempre está ajeno a sus conversaciones por la barrera de la lengua, podemos entrar en los verdaderos temas de la película. Al desarrollarse la acción, vemos cómo los valores racistas están arraigados en las prácticas y la formación cultural de un sector grande de la población española.

En las dos películas está claro que la irrupción de la figura marginal del africano en la psique provincial de las costumbres e identidades españolas reubica nuestro pensamiento actual sobre lo que significa ser español. Los eventos y experiencias de la película desbaratan el ámbito cómodo y homogéneo en que vivían los personajes. Éstos se sienten cómodos ahuyentando lo ajeno, manteniendo una actitud hermética frente al otro. Como una subclase explotada y subordinada, los inmigrantes ilegales se han visto discriminados por los prejuicios muy arraigados de las poblaciones locales en cuya esfera de repente han entrado. Los protagonistas de las dos películas, Alou y Ombasi respectivamente, llegan clandestinamente a la costa de Almería en las peligrosas pateras que cruzan el Mediterráneo. Son sólo dos ejemplos entre los innumerables indocumentados que arriban para alimentar la economía informal española como trabajadores mal pagados, temporeros y desprotegidos. Las dos películas articulan la experiencia transnacional de los inmigrantes y exiliados económicos, pero lo hacen con dos estilos muy distintos.

También Saïd, de Llorenç Soler (1998), cuenta la historia de Saïd y las duras condiciones de vida que tienen los inmigrantes magrebíes en nuestro país.

En un primer momento, la representación que el cine nos muestra, no coincide con la realidad sociológica de la inmigración. La representación artística del inmigrante en España está "africanizada", es decir, hay una mayoría de textos literarios, teatrales y artísticos que se centran en el origen del inmigrante subsahariano, mientras que en la realidad, ese inmigrante no llega al 5 por ciento de la población inmigrante que recibimos. Hay muchas razones para entender esta africanización de la inmigración, como la mayor diferencia racial, la situación de pobreza o el discurso del paso del Estrecho, que es un tema muy tratado porque reúne una serie de componentes artísticos significativos, como su vinculación con los relatos de viajes, el cruce hacia un futuro Edén, la muerte, la tragedia, la fuerza de la naturaleza. 
El cine español ha tenido, tradicionalmente, una mirada prejuiciada respecto a Marruecos y sus gentes. Sin embargo, en el último decenio, se va produciendo un cambio sustancial parejo a una nueva realidad construida sobre las duras condiciones de la inmigración. El estereotipo del moro, sensual y violento, va siendo sustituido por un caleidoscopio de personajes y situaciones que distorsionan la figura estereotipada del marroquí dándole unos perfiles plurales y, en general, positivos. El repaso a la filmografía española más reciente permite ilustrar esta transformación dejando constancia, a la vez, que más allá de la mirada sobre ellos, las películas seleccionadas nos invitan a un saludable ejercicio de crítica sobre nosotros mismos.

Debe agradecerse a directores como Montxo Armendariz (Las cartas de Alou, 1990), Antonio Chavarrías (Susanna, 1996) Llorenç Soler (Saïd, 1998), José Luis Guerín (En construcción, 2000) o Chus Gutiérrez (Poniente, 2002) el descentramiento del punto de vista dominante y la ruptura de los estereotipos tradicionales en unos filmes que, con mayor o menor fortuna, suponen tanto una llamada de atención sobre la condición de inmigrante como una reflexión sobre la propia sociedad española, que para nada sale bien parada en el envite.

El estudio de la figura de la inmigración en España en las últimas décadas es interesante, entre otras razones, porque es una forma de acercarse a la propia identidad española, en cuanto que representa la imagen del "otro" contemporáneo. Y es que pocos fenómenos tienen tanta repercusión en la construcción de la identidad cultural de una sociedad como los movimientos migratorios. Ello ha determinado que el cine español abra su elenco de películas a la narración de otros procesos migratorios hacia España.

Paralelamente al aumento de inmigrantes en España, el cine ha venido alejándose de una representación exclusiva de la inmigración subsahariana, y ha prestado atención a los flujos migratorios procedentes de otros Estados.

La emigración de los países del Este se narra magníficamente en El sudor de los ruiseñores, de Juan Manuel Cotelo, 1998, sobre un violonchelista rumano que llega a Madrid. y trata de ganar el dinero suficiente para poder traer a su esposa y a su hija.

La realidad de los emigrantes cubanos, se refleja perfectamente en Cosas que dejé en la Habana (1999) de Manuel Gutiérrez Aragón. En esta película, la mujer tiene ya una importancia sustancial, ya que narra la historia de tres jóvenes cubanas que buscan trabajo en Madrid donde viven con una tía. Es una interesante película a pesar de que los estereotipos se suceden en ella, tanto en lo que se refiere a las cubanas recién llegadas, que procurar una típica integración en el medio, la tía, que ha hecho simbiosis con el entorno, como los diferentes personajes españoles, que responden a etiquetas previstas.

En 1999, Iciar Bollain realizó Flores de otro mundo, película que nos muestra una caravana de mujeres -extranjeras y españolas- que llega a un pueblo con el fin de establecer relaciones con los solteros de la población. Es, 
posiblemente, la película en la que el problema de la mujer inmigrante, se ve con mayor realismo, sobre todo en lo que se refiere al poder masculino en las relaciones -incluida la violencia corporal-y a las dificultades de ser aceptadas sus diferencias por la cultura tradicional.

Una interesante película es Princesas (2005), en la que Fernando León de Aranoa, director y guionista narra de forma esplendida la amistad de dos prostitutas de calle, una emigrante y otra española, luchando juntas en una sociedad que les da la espalda. En el año 2005 el cine español ha tratado el problema de la mujer emigrante y su relación cultural, laboral y social desde diversos puntos de vista.

Una obra muy importante es la película 14 kilómetros (2007) Espiga de Oro en la semana de Cine de Valladolid, de Gerardo Olivares, cuyo nombre surge de la distancia que separa África de Europa, pero que también es la barrera que aleja los sueños de millones de africanos que piensan en Europa. En África hay millones de personas cuyo único objetivo es entrar en Europa porque el hambre no entiende de fronteras ni de barreras. Catorce kilómetros es la distancia que separa África de Europa, pero también es la barrera que aleja los sueños de millones de africanos que piensan en España, Francia u otro país occidental como la única alternativa para huir del hambre y de la miseria. De la mano de tres jóvenes africanos -Violeta, Buba y Mukela- el espectador recorre un tortuoso viaje a través Mali, Níger, Argelia y Marruecos para conocer lo que nunca enseñan los medios de comunicación. El autor estima que las imágenes y noticias que trasladan a diario los medios de comunicación, con la llegada de los cayucos a las costas de las islas Canarias, sólo muestra la punta del iceberg de un drama gigantesco. Esas imágenes de rostros exhaustos dan buena fe de la dureza del viaje, un viaje que tiene su punto de partida a miles de kilómetros de distancia y que puede durar más de un año.

Inspirada parcialmente en hechos reales, Chus Gutiérrez realizó en 2008 Retorno a Hansala, que narra la historia de Martín, un empresario funerario con problemas económicos, que encuentra en el cadáver de uno de los muchachos marroquíes muertos en el Estrecho

El cine español ha indagado, además en problemas muy específicos de los procesos migratorios. Así en Pobladores (2006) de Manuel García Serrano, se muestra la vida de un colegio público del madrileño barrio de Vallecas. A través de él conoceremos la realidad de dos familias inmigrantes, una marroquí y otra ecuatoriana, y viajaremos con ellas a sus países de origen para conocer la realidad que les ha traído a España. Hiyab, cortometraje español de 2005. (8 min), dirigido por Xavi Sala, muestra cómo Fátima se enfrenta a su profesora porque no quiere quitarse el velo islámico.

La rapidez con que se ha producido la inversión de los procesos migratorios en España, ha provocado que las respuestas a los procesos migratorios no hayan sido siempre las adecuadas, y en su estudio, tenemos que tener en consideración que detrás de estos procesos migratorios opera una gran variedad 
de factores que pueden clasificarse en dos grandes categorías ${ }^{13}$ : fuerzas de atracción que ejercen los Estados de destino (crecimiento y desarrollo de la economía; proximidad geográfica, histórica o cultural; la ausencia de controles adecuados de entrada, etc), y fuerzas de expulsión ejercidas por los Estados de origen (condiciones económicas, sociales o políticas; crisis económicas, pobreza, etc), fuerzas que se ven potenciadas por el actual proceso de globalización.

La entrada de una gran masa de inmigrantes en los últimos diez años ha tenido un impacto muy importante sobre la realidad económica, social y cultural de nuestro país: un mayor aumento de la población; el rejuvenecimiento de la misma, y estos efectos demográficos se trasladan al ámbito económico (mercado de trabajo; mercado de la vivienda; balanza de pagos) e implica al Estado de Bienestar (educación; sanidad; servicios sociales, etc) ${ }^{14}$

Esta realidad, y las transformaciones políticas y socioculturales que ha sufrido España, se han representado en el cine de los últimos quince años, mediante películas de diferentes estilos.

Además de en las películas anteriormente indicadas, los extranjeros afincados en España han comenzado a tener cabida dentro del cine protagonizando películas como La búsqueda de la felicidad (Albert Abril, 1993), Ciudadanos bajo sospecha (Llorenç Soler, 1993), Souvenir (Rosa Vergés, 1994), En la puta calle (Enrique Gabriel, 1996), La sal de la vida (Eugenio Martín, 1996), Susanna (Antonio Chavarrías, 1996), Menos que cero (Ernesto Tellería, 1996), El sudor de los ruiseñores (Juan Manuel Cotelo, 1998), El faro (Manuel Balaguer, 1998), Sobreviviré (Alfonso Albacete y David Menkes, 1999), Tomándote (Isabel Gardela, 2000), El traje (Alberto Rodríguez, 2002), La novia de Lázaro (Fernando Merinero, 2002), Los novios búlgaros (Eloy de la Iglesia, 2003), Extranjeras (Helena Taberna, 2003), Tánger (Juan Madrid, 2004), o Agua con sal (Pedro Pérez Rosado, 2005).

Pero también, en otras películas, los emigrantes han aparecido como secundarios imprescindibles o simplemente como figuras del entorno de los protagonistas: Alma gitana (Chus Gutiérrez, 1995), Hola, ¿estás sola? (Icíar Bollaín, 1995), Taxi (Carlos Saura, 1996), El color de las nubes (Mario Camus, 1997), Chevrolet (Javier Maqua, 1997), Torrente, el brazo tonto de la ley (Santiago Segura, 1997), Finisterre (Xavier Villaverde, 1998), París-Tumbuctú (Luis G. Berlanga, 1999), La fuente amarilla (Miguel Santesmases, 1999), Se buscan fullmontis (Alex Calvo Sotelo, 1999), Sé quien eres (Patricia Ferreira, 1999), Pídele cuentas al rey (José Antonio Quirós, 1999), Leo (José Luis Borau, 2000), Adiós con el corazón (José Luis García Sánchez, 2000), Mi dulce (Jesús Mora,

${ }^{13}$ Vid. BORJAS, G.J.- The Economic Análisis of Inmigration en Handbook of Labor Economics, Vol. 3 A. North Holland, 1999.

${ }^{14}$ Vid. Tres factores clave para una política de inmigración: apertura, control e integración, Círculo de Empresarios, noviembre-diciembre de 2006. 
2000), A mi madre le gustan las mujeres (Inés París y Daniela Fejerman, 2001), En construcción (José Luis Guerin, 2001), Salvajes (Carlos Molinero, 2001), Torrente 2. Misión en Marbella (Santiago Segura, 2001), Canícula (Álvaro García-Capelo, 2001), o Ilegal (Ignacio Vilar, 2002)..$^{15}$

La política de inmigración, de acuerdo con las recomendaciones comunitarias, debe partir de la idea de que la integración es un proceso social dinámico, prolongado en el tiempo -tiene, por lo tanto, que ser continuamente reproducido y renovado-, que requiere un esfuerzo bidireccional de adaptación a la nueva sociedad, tanto por la población inmigrada, como de la sociedad receptora, y que debe estar delimitado por los valores básicos de la UE, y de la propia Constitución española, valores plasmados en el art. $1 \mathrm{CE}$, en su relación con el artículo 10, configuradores del marco de valores y normas básicas dentro del cual debe articularse la integración.

La necesidad de adoptar un enfoque integral o global en un marco de cooperación en el que las políticas de integración se dirigen a la ciudadanía en su conjunto, y que las actuaciones públicas deben ir orientadas a promover y garantizar el acceso normalizado de la población inmigrada a los servicios, mediante la incorporación transversal a todas las políticas públicas, constituyen las premisas que configuran la filosofía política del Plan, que se basa en los principios de igualdad y no discriminación -equiparación de derechos y obligaciones de la población inmigrada y autóctona, dentro del marco de los valores constitucionales básicos-; el principio de ciudadanía-reconocimiento de la plena participación cívica, social, económica, cultural y política de los inmigrantes-, y el principio de interculturalidad-mecanismo de interacción entre las personas de distintos orígenes y culturas, dentro de la valoración y el respeto de la diversidad cultural-,

En la actualidad, en el ámbito internacional muchas películas contienen en su interior las huellas de un diálogo entre culturas, e incluso en ocasiones parecen exigir del espectador una meditación acerca de la identidad. El cine español no ha querido ser ajeno a esta problemática y desde hace algunos años existe un creciente interés por la interculturalidad, encarnada en historias donde aparecen personajes de distinto origen cultural en convivencia, contacto o desencuentro, de tal manera que a veces de forma tangencial, y otras como núcleo central de la trama, las relaciones interculturales ya no están ausentes de nuestro cine. Resulta curioso detectar que, en unos pocos años, la aparición del inmigrante como personaje cinematográfico se ha multiplicado. Pero hay que tener en cuenta que esta presencia posee dos etapas radicalmente opuestas, aunque paralelas a los cambios sociales y a la evolución de la sociedad de nuestro país. Así, antes de 1975 encontramos -generalmente- al

15 "El diálogo intercultural en el cine español contemporáneo: entre el estereotipo y el etnocentrismo". Inmaculada Gordillo, Comunicación Revista Internacional del Departamento de Comunicación Audiovisual, Publicidad y Literatura. Número 4, 2006, págs. 207-222. 
"otro" como personaje de acogida. Durante muchos años, la figura del emigrante en el cine ha sido representada por el español que tenía que dejar su tierra en busca de un trabajo que le permitiese una vida mejor con filmes como Alba de América (Juan de Orduña, 1951), Españolas en París (Roberto Bodegas, 1970) o Gallego (Manuel Octavio Gómez, 1987) entre otras muchas. La segunda etapa podríamos considerar que empieza a partir de 1990. Las cartas de Alou (Montxo Armendáriz) fue la primera película en inaugurar el género de las narrativas de inmigración ${ }^{16}$.

Y el cine español no ha sido uniforme en el tratamiento del inmigrante, y de los procesos migratorios. Así, encontramos estereotipos sexuales o miradas estereotipadas por parte de otros personajes en numerosos filmes (Cosas que dejé en la Habana, El rey del mambo, Finisterre, Adiós con el corazón, En la puta calle, Princesas, Flores de otro mundo, Torrente, Habana Blues, Miss Caribe...). En general es el estereotipo habitual en relación, sobre todo, a negros y cubanos tanto hombres como mujeres. Es muy usual la figura de la mulata desinhibida y ambiciosa que usa su sexualidad como arma para controlar a los hombres, ya que no hay que olvidar que el uso de la mulata como cuerpo-símbolo de la cultura cubana tiene ya su origen en el XIX y Cuba ha figurado mucha veces como un escenario saturado de sensualidad y caracterizado por el exceso; sin duda una metáfora, en la época, de la desinhibición sexual. Siguiendo con los estereotipos culturales, el emigrante es considerado a menudo como un delincuente, relacionado con la droga, la criminalidad y la prostitución. Así, encontramos ejemplos de inmigrantes rozando la criminalidad en La novia de Lázaro, En la puta vida, Cosas que dejé en La Habana, ¡Átame!, Atún y chocolate, El traje, Alma gitana, Susanna, Chevrolet y Saïd Saïd entre otras películas.

Sin embargo, también en el cine español existen obras que logran burlar al estereotipo gracias al paulatino conocimiento y la convivencia. Algunas películas nos aportan una visión positiva de unas relaciones que nunca empiezan bien, pero que al final consiguen llegar a buen término. Se trata de

${ }^{16}$ También existen numerosos cortometrajes que, directa o indirectamente han abordado el tema: Cabeza de turco (Jorge Borrell, 1993); ;Que vienen, que vienen! (Gustavo Vallecas, 1995); Estrecho Adventure (Valeriano López Domínguez, 1996); La línea del Estrecho (Javier Gil, 1997); Todos os llamáis Mohamed (Maximiliano Lemcke, 1998); Lalia (Silvia Munt,1999); Marionetas de plomo (Rafael Montesinos, 1999); El conde inglés (Clara López Rubio, 2001); Bamboleho (Luis Prieto, 2001); Sin documentos (Joaquín Martínez, 2001); Singladuras (Oscar de Gispert, Lucas Maldonado, Diana Arias, 2002); Fora do Brasil (Torrent Carles Aledo, 2002); Y tú ¿qué harías? (Emiliano Melgarejo, 2002); Fresa amarga (Película colectiva, Intermedia producciones, 2003); El niño que jugaba con trenes (Jorge Blas Borroy, 2003); Un cuento chino (Antonio Llorens, 2003); Amigo no gima (Iñaki Peñafiel, 2003); Español para extranjeros (José Luis Garcia Sánchez, 2004); Verja (Alfonso Ungría, 2004); Platicando (Marisa Lafuente, 2004); Sin recortes (María José Aguilar, 2006); África llora aquí (María José Aguilar, 2007) o Aquí cabemos todos (María José Aguilar, 2007). 
aquellas situaciones en las que el español se pone en contacto con un inmigrante irregular, desarrollándose, con el conocimiento y la solidaridad mutua, unas relaciones interculturales basadas en la amistad y en el respeto. Las diferencias permiten entonces una comunicación intercultural en condiciones de igualdad. Algo parecido observamos en Princesas (la prostituta española Caye -Candela Peña- y la dominicana Zulema -Micaela Nevárez- se apoyan mutuamente), Agua con sal (Marijo -Leyre Berrocal-, una prostituta y obrera valenciana y la cubana Olga -Yoima Valdés-, su compañera en la fábrica); o Sobreviviré (la vida gris de Marga se ve marcada por la fuerza y el optimismo de la cubana Rosa). Incluso en ocasiones es posible una relación más profunda, con implicaciones de pareja pero con consecuencias de rechazo social. Es el caso de las parejas multiculturales, de las que el cine español también empieza a dar cuenta. En Flores de otro mundo de Iciar Bollaín. No es el único modelo de parejas multiculturales: también encontramos ejemplos en Saïd, Susanna, Cosas que dejé en la Habana, Hola ¿estás sola?, La novia de Lázaro, Las cartas de Alou, Sobreviviré, Maité, Cuarteto de la Habana, Pata negra, Habana Blues, etc. 